Becaria de investigación en la Universidad de Alicante. Realiza su doctorado sobre narradoras mexicanas contemporáneas. Actualmente está integrada en el proyecto de investigación «Relaciones literarias entre España y América Latina», dirigido por Carmen Alemany, de la Universidad de Alicante.

\title{
COMO AGUA PARA CHOCOLATE Y MALENA ES UN NOMBRE DE TANGO: EN BUSCA DE UNA GENEALOGÍA PERDIDA
}

\author{
PaOla MADRID MOCTEZUMA
}

1

Susana Reisz, "Hipólesis sobre el tema escritura femenina e hispanidad», Tropelías, Revista de teoría de la literatura y literaiura comparada, nำ 1, Zaragoza, Universidad de Zaragoza, 1990, pp. 199-213.

2

La literaiura conocida como «femenina» es considerada por algunos sectores de la crítica como «literatura marginada" o "baja literatura», junto a otras formas discursivas como la literatura didáctica, el folletín, la novela rosa, la novela del oeste, policíaca, el cómic, la literatura erótica, la poesía de "maldezir», etc., Beatriz González Stephan, «'Para comerte mejor': cultura calibanesca y formas literarias alternativas», Casa de las Américas, $n^{\circ} 185,1991$, p. 81.

Como agua para chocolate y Malena es un nombre de tango: en busca de una genealogía perdida PAOLA MADRID MOCTEZUMA
Si echamos un vistazo a la producción narrativa escrita por mujeres en el ámbito hispánico e hispanoamericano desde los años setenta hasta nuestros días, comprobamos que es especialmente deslumbrante. Susana Reisz ${ }^{1}$ explica que se trata de un fenómeno que afecta a ambos lados del Atlántico y que ella califica como «un tardío 'boom' hispánico femenino». Son narradoras que se vinculan por características tales como la edad, el éxito editorial, la accesibilidad de sus obras al gran público, su relación con el periodismo y, en muchos casos, el cuestionamiento por parte de la crítica de la calidad literaria de sus novelas ${ }^{2}$. La obra de autoras españolas como Monserrat Roig, Rosa Montero, Carme Riera, Esther Tusquets, Lourdes Ortiz, Soledad Puértolas, Maruja Torres o Almudena Grandes se inscribe dentro de esta eclosión de narrativa femenina, mientras que en Hispanoamérica destacan los nombres de las chilenas Isabel Allende y Marcela Serrano, la argentina Luisa Valenzuela, las puertorriqueñas Rosario Ferré y Ana Lydia Vega o las mexicanas Ángeles Mastretta y Laura Esquivel.

Entre estas narradoras se pueden espigar una serie de constantes temáticas y estilísticas, fruto de un contexto cultural, generacional y vital, como por ejemplo los acontecimientos del Mayo francés de resonancia mundial, la represión cultural en sus países a causa de sistemas políticos totalitarios, la influencia de la cultura de masas, el cine, la música o la incidencia del ambiente feminista que se encontraba en pleno auge en los años setenta. Como resultado, los textos de estas mujeres se caracterizan por rasgos impugnadores que desarticulan el discurso dominante: la primacía de lo sensorial, lo erótico, la parodia e ironía, lo poético, la fragmentariedad, la ambigüedad, la disolución de fronteras entre los géneros literarios, la reinterpretación de motivos filosóficos y culturales, la alteración de los esquemas femeninos tradicionales y la búsqueda, en mayor o menor medida, de una identidad perdida son constantes de esta narrativa.

Hemos tomado dos ejemplos paradigmáticos de novelas donde la reconstrucción del sujeto femenino se formula a partir de la recuperación simbólica de una genealogía: Como agua para chocolate (1989) de la mexicana Laura Esquivel y Malena es un nombre de tango (1994) de la española Almudena Grandes. Esta reconciliación entre mujeres que supone el concepto de genealogía dará paso a un proceso de liberación a través de la rehabilitación de cauces simbólicos como el rol del cuerpo o el derecho a la voz y a la escritura como culminación de este proyecto de identidad.

\section{APROXIMACIÓN A UNA GENEA- LOGÍA FEMENINA}

«...es necesario (...) que afirmemos la existencia de una genealogía de mujeres. Una genealogía de mujeres dentro de nuestra familia: después de todo, tenemos una madre, una abuela, una bisabuela, hijas. Olvidamos demasiado esta genealogía de mujeres puesto que estamos exiliadas (...) en la familia del padre-marido; dicho de otro modo, nos vemos inducidas a renegar de ella. Intentemos situarnos dentro de 
esta genealogía femenina, para conquistar y conservar nuestra identidad. $Y$ no olvidemos tampoco que ya tenemos una historia, que en la historia, aunque haya sido difícil, han existido algunas mujeres y que con demasiada frecuencia las olvidamos». Luce Irigaray $^{3}$

Desde un punto de vista teórico, la tendencia crítica conocida como «nuevo feminismo francés» se ha encargado de arrojar luz sobre el concepto de genealogía. Hélène Cixous o Luce Irigaray señalan que una genealogía femenina se basa en la recuperación de las relaciones entre mujeres y sobre todo en el restablecimiento del lazo con la madre. Para estas críticas, este vínculo ha sido devastado por la cultura patriarcal que se asienta sobre la base de un matricidio 4 . Si bien es cierto que lo que más se ha criticado al nuevo feminismo francés es su alejamiento de la realidad por ser muy interpretativo y teórico, algunas de sus propuestas resultan productivas para aplicarlas al análisis de diversas obras escritas por mujeres. En el caso que nos ocupa, la proyección del concepto de genealogía se dirige hacia diversos frentes: por un lado, se indaga en los antecedentes simbólicos e históricos que unen a las mujeres entre sí y por otro, se recupera la relación de la mujer con la maternidad en toda su extensión.

En la narrativa femenina escrita en México, la práctica genealógica se concreta a partir de 1968 (año que genera un cambio abrupto en la narrativa a causa de la Matanza de Tlatelolco) en obras donde se buscan o cuestionan las raíces familiares. Como ejemplos podemos citar La morada en el tiempo, de Esther Seligson (1981), Las genealogías de Margo Glantz (1981), La familia vino del norte, de Silvia Molina (1987), La flor de Lis, de Elena Poniatowska (1988), Mejor desaparece y Antes, de Carmen Boullosa (1988, 1989, respectivamente), y Como agua para chocolate, de Laura Esquivel (1989) $)^{5}$.

Las escritoras españolas de esta época también van a explorar la relación genealógica de las protagonistas de sus novelas: Esther Tusquets plasma en El mismo mar de todos los veranos que el fracaso vital de Elia se debe, en buena parte, a la madre; Ana María Moix, en su primera novela, Julia, busca cuál es el origen de su existencia degradada y concluye, como en la novela anterior, que la causante es su madre; Matute, Roig y Riera establecen rela- ciones subversivas con la figura materna y Almudena Grandes representa sagas femeninas vinculadas por relaciones simbólicas más que por consanguinidad.

En Como agua para chocolate y $\mathrm{Ma}$ lena es un nombre de tango estas relaciones son complejas y desarrolladas bajo signos opuestos, en ocasio-

nes irreconciliables. El enfrentamiento fraternal y materno-filial dará paso a la búsqueda de afinidades con otras mujeres, creando nuevas genealogías cuyos mecanismos de cohesión serán, entre otros, el alma creadora, las ansias de libertad, la primacía de las pulsiones, la ruptura con la tradición y la resemantización de la maternidad. Tanto en una como en otra novela aparece una fuerte rivalidad entre hermanas. La propia Almudena Grandes comenta en una entrevista, a propósito de Malena es un nombre de tango, que «...no se trata de una historia de mujeres buenas y mujeres malas, eso no. Es la historia de dos hermanas, Reina y Malena, mellizas, figuras protobíblicas en cuanto que en la Biblia hallamos en síntesis esa confrontación eterna entre la mujer fuerte y la mujer débil» ${ }^{6}$.

Desde el comienzo de Malena es un nombre de tango conviven dos genealogías que arrancan desde tiempos inmemoriables y que son incapaces de cruzarse: la de las Reinas (mujeres apegadas a la tradición, que viven en el mundo de las apariencias) y la de las Magdalenas (que se mueven por la fuerza de la sangre y por ello se consideran las «ovejas negras de la familia»). Parece que el nombre, a modo de estigma, maldice a estas mujeres conduciéndolas por caminos paralelos:

«De puro lejano, nadie recuerda cuándo comenzó a haber al menos una mujer llamada Reina en cada una de las generaciones de mi familia materna. Nadie recuerda tampoco de dónde arranca la línea de las Magdalenas, que ojalá muera conmigo; (...) dos cadenas paralelas de mujeres homónimas, abuelas y nietas, tías y sobrinas, cuyos eslabones se enredan sistemáticamente entre sí, (...) serpentean entre mis apellidos desde hace siglos»?
3

Luce Irigaray, «El cuerpo a cuerpo con la madre», El cuerpo a cuerpo con la madre. El ofro género de la naturaleza. Otro modo de sentir, Barcelona, Labal, 1985, p. 11

\section{4}

Irigaray y Cixous reinterpretan los mitos griegos para justifcar el matricidio, y ponen como ejemplo La Orestíada, en la que la madre, Clitemnestra, es asesinada por su hijo Orestes para res tablecer el orden patriarcal: «El gesto de Orestes, neutro, ni masculino ni femenino, mitad activo, mitad pasivo, ni criminal ni no culpable, rubrica la suspensión del gran reino de las madres. Alba del falocentrismo". (Hélène Cixous, La risa de la medusa, Barcelona, Antrhopos, 1995, p. 72).

5

Ejemplos tomados de Margo Glantz, "Las hijas de la Malinche», Karl Khout (ed.), Literatura mexicana hoy, Madrid, Iberoamericana, 1995, p. 122.

\section{6}

Francisco J. Satué, «Almudena Grandes», Urogallo, Revista literaria y cultural, septiembre-octubre, 1994, n 100-101, p. 24.

7

Almudena Grandes, Malena es un nombre de tango, Barcelona, Tusquets Editores, 1999, (1994 $1^{\mathrm{s}} \mathrm{ed}$.), pp. 33-34.

Como agua para chocolate y Malena es un nombre de tango: en busca de una genealogía perdida PAOLA MADRID MOCTEZUMA 


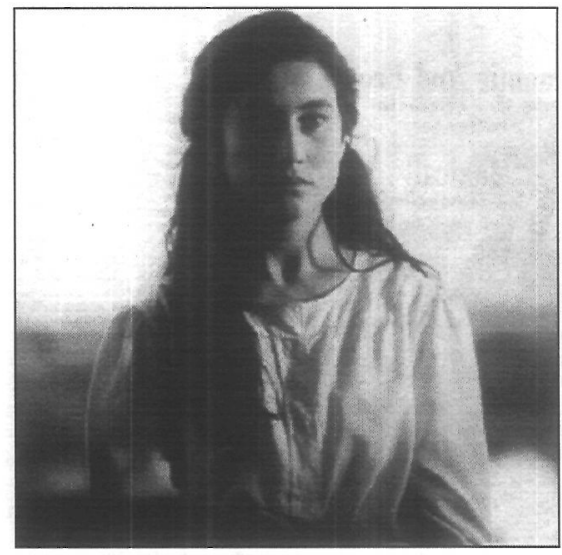

Lumi Cavazos es Tita en la versión cinematográfica de Como agua para chocolate, dirigida por Alfonso Arau (1992).

8

Ibid, p. 42.

9

Ibid, p. 86.

10

Esta recuperación por parte de una autora de finales del siglo $X X$ de un viejo concepto masculino acerca de la naturaleza de la mujer responde a la mimetización paródica de los esquemas parriarcales que la crítica literaria feminista argumenta como mecanismo de deconstrucción.

11

Ibid, p. 90.

12

Ibid, p. 90.
Como agua para cbocolate y Malena es un nombre de tango: en busca de una genealogía perdida PAOLA MADRID MOCTEZUMA
Malena y Reina, hermanas mellizas, repiten el mismo esquema de comportamiento que caracteriza a la generación anterior, la de su madre Reina y la tía Magda; mantienen una relación especular, pero con la peculiaridad de que el reflejo en el espejo está movido. De personalidades antagónicas, reformulan mitos que asolan a los hombres de todos los tiempos, como el cainismo. Lo único que han compartido es la cálida estancia en el mismo útero, porque desde el momento de nacer cada una se mostró muy diferente: Reina como un bebé debilucho primero y como una joven de extrema fragilidad después, mientras que Malena desde pequeña demostró una magnífica salud reflejada en su vigoroso aspecto; Reina creció siendo una niña perfecta de acuerdo con el canon social de la España de la Transición y Malena como una rebelde e impulsiva. Esto hace que Malena crezca con la creencia absoluta de haber nacido por error y de que el mundo estaba creado a la medida de su hermana:

"Reina y yo no nos parecemos en nada, Reina es mucho más buena que yo».

«Éramos tan diferentes que el abismo que separaba nuestros rostros, nuestros cuerpos, llegó a parecerme lo menos importante de todo, y cuando la gente correspondía con una mirada de asombro a la confidencia de que ambas éramos mellizas, yo pensaba, ya está, ya se han dado cuenta de que ella es una niña y yo soy otra cosa. (...) El mundo, el pequeño mundo donde vivíamos entonces, no era otra cosa que el exacto lugar que Reina habría escogido para vivir...»"

Esta diferencia incontrovertible hace a Malena negar su propia naturaleza femenina y a rezar a la Virgen de color aceitunado (aquélla que pertenece a su misma estirpe y no la blanca e inmaculada) para que la convierta en un chico.

Reina, por su parte, es la portadora del concepto patriarcal del eterno femenino ${ }^{10}$, ya que hace pervivir tanto en su persona como en la de su hermana la articulación bifronte de la mujer como ángel y demonio, dicotomía María-Eva (o María-Lilith), síntesis del Bien y del Mal. De Reina se dice que es una «pequeña y pérfida mujer fatal», pues tras su máscara lán- guida y delicada de blancura transparente y belleza marmórea subyace una envidiosa mujer de naturaleza destructiva. En Malena esta dualidad creada artificialmente por Reina responde a un retorcido «juego de crías» llamado «el Juego», consistente en que Reina-diosmadre juzga la bondad de los actos de Malena; cuando la ha de reprender, en vez de llamarla por su nombre la rebautiza como «María» (el primer nombre de Malena, altamente relacionado con la naturaleza dual del eterno femenino) despojándola de su identidad y limitando los actos más espontáneos de la hermana (como comer entre horas, leer fotonovelas o vestir descuidadamente):

«...seguí jugando al Juego, aquel rito solemne disfrazado de broma infantil que nunca llegaría a extinguirse solo (...) porque a mí se me olvidaba con mucha frecuencia pero Reina lo tenía siempre presente, y antes o después deslizaba en mis oídos un discreto susurro para devolverme a los dominios de aquel detestable apodo, María, que tantas veces consiguió anular mi voluntad sin lograr nunca hacerme mejor, $(. ..) »^{11}$

La diferenciación entre una y otra se extrema en la propuesta maligna que Reina formula acerca de dos tipos de mujeres, y que Fernando, amor eterno para Malena, verbaliza ingenuamente en «tías para follar y tías para enamorarse». Malena se autocondenará en la primera categoría, hasta que en la madurez consigue escapar de esa estigmatización. Esta oposición binaria entre genealogías queda resumida en una filosofía práctica e intuitiva, pero no por ello menos cierta, de la tía Magda:

«- ¿Sabes cuál es la única diferencia entre una mujer débil y una mujer fuerte, Malena? - Me preguntó Magda, y yo negué con la cabeza-. Que las débiles siempre se pueden montar en la chepa de la fuerte que tengan más a mano para chuparle la sangre, pero las fuertes no tenemos ninguna chepa en la que montarnos, porque los hombres no valen para eso, y cuando no queda más remedio, tenemos que bebernos la nuestra, nuestra propia sangre, y así nos va» ${ }^{12}$.

En el caso de Como agua para chocolate, el choque fraternal queda signado en la relación entre Rosaura y Tita, metaforizada en el contacto «del agua en aceite hirviendo». Desde niñas muestran naturalezas diferentes: Tita hace 
de la cocina su universo propio, su lugar de juegos y su modo de vida, mientras que Rosaura no tiene sazón, es torpe para cocinar y melindrosa para comer. Pero será en su juventud cuando estas diferencias se acentúen y culminen con la traición de Rosaura al casarse con el novio de su hermana:

«De ahí nació la aversión de Nacha para con Rosaura y la rivalidad entre las dos hermanas, que culminaba con esa boda en la que Rosaura se casaba con el hombre que Tita amaba» ${ }^{13}$.

No siempre Rosaura y Tita fueron rivales, y por ello Tita recuerda con nostalgia los años de su infancia cuando aún no tenían que disputarse el amor de un hombre y ella ignoraba todavía que le estaba prohibido el matrimonio.

Si los vínculos entre hermanas se ven debilitados, el lazo con la madre de estas mujeres se rompió con el corte del cordón umbilical; la relación de su protagonista, Tita, con su madre biológica, Mamá Elena, queda inscrita en términos de matrofobia. Mamá Elena es el prototipo de mater dolorosa, castrada y castradora, en la que pervive la ley del patriarcado, pues es guardiana del derecho paterno ${ }^{14}$. Concibe a la mujer como un ser dependiente, obediente y sumiso, tal y como ha sido considerada por los hombres a lo largo de la historia. El único lazo vinculante con su hija Tita es una obsoleta ley que se transmite a las hijas menores de su familia (con lo que los varones quedan milagrosamente excluidos) a las que se les priva de su derecho al matrimonio para cuidar de su madre hasta que muera. La relación materno-filial entre Tita y su madre queda cercenada desde el nacimiento de la hija y se materializa en la incapacidad de Mamá Elena para alimentar a Tita. Aún más: esta madre se caracteriza por su capacidad destructiva, aniquiladora:

«Indudablemente, tratándose de partir, desmantetelar, desmembrar, desolar, destetar, desjarretar, desbaratar o desmadrar algo, Mamá Elena era una maestray ${ }^{15}$.

Mamá Elena se alza como arquetipo de la madre devoradora por el efecto retroactivo del consumo que de ella se hace en su vientre. Su presencia genera temor, simbolizado en un aliento gélido capaz de extinguir la llama de los corazones de quienes la rodean. Esta autoridad devastadora se concreta sobre todo en su relación con Tita (y de forma ancilar con Gertrudis). Todas las actividades que Tita ejerce son criticadas por su madre, aunque éstas rocen la perfección: para Mamá Elena la comida tiene demasiada sal o está insípida, la ropa está arrugada o el agua del baño no está lo suficientemente caliente. Por su parte, Rosaura es heredera del orden atávico instaurado por la tradición y reproduce la actitud de Mamá Elena; pertenece, como ella, a la saga de mujeres frustradas y oprimidas que se preocupan más por aparentar que por vivir:

«Y mira, a mí me tiene muy sin cuidado si tú y Pedro se van al infierno por andarse besuqueando por todos los rincones (...) mientras nadie se entere, a mí no me importa» ${ }^{16}$.

Pretende perpetuar una tradición familiar en su hija Esperanza pero al igual que Mamá Elena, su falta de leche materna rompe el lazo genealógico con la hija, acabando así con el reino de estas madres demonizadas.

En el caso de Malena es un nombre de tango, la madre de Malena, Reina, es resultado de la ideología sexual y cultural del régimen franquista; víctima del sistema, se convierte en la reproductora de sus esquemas (con especial encono hacia Malena). Un ejemplo sintomático de la represión de esta mujer es su reacción ante la pérdida de virginidad de Malena (descubierta, cómo no, por culpa de Reina en la consulta del ginecólogo):

«Y no me dolió la bofetada que me pegó mamá apenas me tuvo delante, ni que me gritara que no quería saber de mí en toda su vida en una sala repleta de gente extraña, ni que me llamara puta a gritos en plena calle. Lo que me dolió fue que, cuando paró un taxi y abrió la puerta para que mi hermana pasara delante - ¡vamos, hija!-, ella ni siquiera se volvió a mirarme ${ }^{17}$.

Pero en quien mejor se articula la maternidad como producto del patriarcado es en Reina-hija. Ella representa lo que Adrienne Rich denomina «maternidad como institución», definida y regulada por la tradición, la religión, el falso sentimentalismo, las costumbres impuestas, mermando la autorrealización fe-
13

Laura Esquivel, Como agua para chocolate, Barcelona, Mondadori, 2000, (1989 19 ed.), p. 37.

74

Aralia López González, «Ética y estética del fuego», Aralia López González (ed.), Sin imágenes falsas, sin falsos espejos. Narradoras mexicanas del siglo $X X$ México, El Colegio de México, 1995, p. 561.

15

Laura Esquivel, Op. cit., p. 114.

16

Ibid, p. 242.

17

Almudena Grandes, Op. cit., pp. 224-225.

Como agua para chocolate y

Malena es un nombre de tango: en busca de una genealogía perdida PAOLA MADRID MOCTEZUMA 
Adrienne Rich, (1978), Nacemos de mujer. La maternidad como experiencia e institución, Madrid, Cátedra, 1996, p. 390.

\section{9}

Almudena Grandes, Op. cit., p. 444.

20

Hélène Cixous, Op. cit., p. 51.

21

La narrativa femenina desde los años setenta adopta distintas posturas para abordar este tema: maternidad como destructora del crecimiento individual de la mujer ly a esto se relaciona el tema del aborto, el de la posible pérdida de competencia profesional, el deseo de independencia frente a la obligación de dar un padre al niñol o como continuidad de un poder vivificador, mítico (dentro de este campo destaca la equiparación de gestar un niño con producir un escrito). En el primer grupo citamos novelas como Meridian, de Alice Walker (1976), Lady Oracle (1976) de Margaret Atwood, Lettera a un bambino mai natto (1975) de Oriana Fallaci o más recientemente Arráncame la vida (1986), de Ángeles Mastretta. El segundo grupo podemos ejemplificarlo con Die Mutter (1975) de Karin Struck, La risa de la medusa (1975) de Hélène Cixous o La casa de los espíritus y Paula (1982, 1994 respectivamente) de Isabel Allende.

\section{2}

Almudena Grandes, Op. cit., p. 398.

23

Ibid, p. 453. menina y la conservación de una autonomía propia e intransferible. Adrienne Rich satiriza este tipo de maternidad cuando escribe lo siguiente:

"Cuando pensamos en la maternidad, se supone que debemos evocar las mujeres rozagantes de Renoir, con niños rosados sobre las rodillas; las vírgenes de Rafael; una madre judía encendiendo las velas en una cocina bien fregada, con su pan junto a la servilleta bien planchadas ${ }^{18}$.

Si bien Reina no es una mujer «rozagante», ejerce el rol de la maternidad en los mismos términos que aquí se enuncian: pasividad, «bondad» incuestionable para con los hijos y ejecución impecable de su trabajo en el hogar. Reina, no sólo es considerada una buena madre sino que es la madre total, pues permite que los niños duerman con ella en cama cuando tienen pesadillas, les fabrica huchas con un tetrabrik, no sale nunca de casa por las noches, y todo, en contraste absoluto con la vida poco ortodoxa de su hermana Malena. Desde la perspectiva de esta última,

«La maternidad, como una droga mágica que todo lo cura, había convertido a mi hermana en una mujer tan sumamente conservadora (...) que había conseguido parecerse físicamente a nuestra madre más que yo» ${ }^{19}$.

Hélène Cixous ${ }^{20}$ denuncia esta maternidad como una trampa consistente en convertir a la madre en una agente cómplice (aun inconscientemente) de la reproducción capitalista, familiarista, falocentrista, en definitiva, en una forma de represión.

En contraste, en ambas novelas se propone una nueva forma de ser madre, vista desde distintos enfoques ${ }^{21}$, pero con un denominador común: el amor. Malena rompe con el tópico de la maternidad como modo de afirmar la identidad femenina; es más, en un primer momento se le presenta como un lastre, destructora de la independencia y del crecimiento intelectual. Esta relación conflictiva se acerca más a la realidad, a los sentimientos contrapuestos y ambiguos que el hecho de ser madre suscita en las mujeres, al choque entre los verdaderos deseos y el comportamiento que la sociedad ha estipulado. En este sentido, la mujer debe dedicarse a la empresa ardua de descubrir qué siente, en lugar de aceptar lo que se le ha inculcado que debería sentir. Ma- lena metaboliza su embarazo del siguiente modo:

"Los lunes por la mañana estaba decidida a abortar y a abandonar a Santiago para corregir de golpe todos los errores que había acumulado durante los últimos tiempos. Los lunes por la noche me preguntaba si sería sensato contradecir la voluntad del destino. Los martes, al levantarme, me decía que si siempre había pensado en tener hijos alguna vez, por que no éste, por qué no ahora. Los martes, al acostarme, me daba cuenta de que abandonar a mi marido sería como dejar caer un bebé de dos meses en el carril central de la Castellana un viernes a las diez de la noche. Los miércoles por la mañana parecía darme cuenta de que dentro de mi cuerpo había un ser vivo, otro cerebro, otro corazón, mi hijo. Los miércoles por la noche dejaba de fumar. Los jueves, antes de levantarme, no era capaz de sentir otra cosa que un bulto amenazante y peligroso, un quiste o un tumor que debería hacerme extirpar a tiempo. Los jueves, antes de acostarme, encendía un cigarro con otro y apuraba los dos hasta el filtro. Los viernes por la mañana me preguntaba por qué había tenido tan mala suerte. Los viernes por la noche estaba decidida a abortar y a abandonar a Santiago para corregir de golpe todos los errores que había acumulado durante los últimos tiempos ${ }^{22}$.

Pese a las contradicciones inherentes al hecho de ser madre, Malena asume este papel con la mejor herramienta posible: el amor. El sufrimiento de Malena ante el complicado nacimiento de su hijo Jaime (Jaime como el abuelo paterno, como el héroe Conquistador), el verle postrado en una cama siendo un recién nacido y su primer contacto corporal en la lactancia fueron suficientes motivos para restablecer su vínculo, aprender a amarlo y luchar por él. Este «nuevo» sentimiento maternal también se hace extensible a su marido Santiago; su posible separación matrimonial se contempla como una suerte de orfandad y por eso Malena no se atreve a tomar la iniciativa:

«Debería haberlo dejado hace mucho tiempo, pero nunca me atreví, porque desde el principio él se convirtió en algo parecido a un hijo grande, durante años he tenido la sensación de tener dos hijos, uno mayor y uno pequeño, y las madres no abandonan a sus cria$\operatorname{turas}(\ldots))^{23}$

Por su parte, Tita asume su maternidad de un modo simbólico. Su castigo por mantener 
relaciones adúlteras con Pedro es un embarazo psicológico y la renuncia a ser madre. Por esta razón ella explora la maternidad a través de Roberto y Esperanza, hijos de su hermana Rosaura. La relación principal que establece en estos términos es la de ayudar a generar vida y sobre todo alimentar. Recordemos cómo colabora en el parto de Roberto, auspiciado por los consejos del espíritu de Nacha:

«(...) el obscuro túnel de un momento a otro se transformó por completo en un río rojo, un volcán impetuoso, en un desgarramiento de papel. La carne de su hermana se abría para dar paso a la vida. Tita no olvidaría nunca ese sonido ni la imagen de la cabeza de su sobrino (...) a Tita le pareció la más hermosa de todas las que había visto en su vida ${ }^{24}$.

Esta descripción del parto en términos físicos y a la vez sublimes es propia de la concepción mítica de la maternidad por parte de algunas narradoras hispanoamericanas ${ }^{25}$ y contrasta con la experiencia de alumbramiento descrita por Almudena Grandes, que condensa angustia y sufrimiento:

"Ellas me decían que empujara, y yo empujaba, (...) yo preguntaba si el niño estaba muerto, y nadie me contestaba porque a mí no me tocaba preguntar, sólo empujar, y yo empujaba, y luego me he preguntado mchas veces por qué no lloré, por qué no me quejé, por qué no me dolí de aquél momento, ahora que estoy segura de que de que nunca en mi vida conoceré otro tan horrible $(. .).)^{26}$

La alimentación de Roberto y Esperanza transforman a Tita en una diosa portadora de vida, personificación de Ceres, pero también en una Virgen morena (como la guadalupana) capaz de transmutar sus acendrados senos en fuente inagotable de leche, en un cuadro maternal de tintes divinos donde ella, Roberto y Pedro son los protagonistas.

La reconciliación de estas mujeres con su propia maternidad les permite fundar una estirpe nueva que les sirve para recuperar una memoria colectiva y construir a su vez una subjetividad propia. Esta matriz simbólica comienza en Como agua para chocolate en la cocina, tradicionalmente vinculada al sexo femenino, que se resemantiza como espacio uterino de calidez y protección, en el que se guisa, se amamanta, se teje, se pare, se escribe, en definitiva, se crea. Nacha, la cocinera india, es la diosa de este recinto sagrado. En ella conviven generaciones de tradición y sabiduría del mundo prehispánico. Nacha, como madre nutricia, a diferencia de mamá Elena, se encarga de la alimentación de Tita a base de «atoles y tés» y también introduciéndola en la gastronomía prehispánica (Tita comía jumiles, gusanos de maguey, acosiles, tepezcuintle, armadillo, etc.). En este sentido, la figura de $\mathrm{Na}$ cha se aproxima a lo que Melanie Klein ha llamado «Dios Madre»27, una especie de diosa omnipotente, proveedora generosa de amor, alimento y plenitud, pero también a la imagen de Tenantzin-Guadalupe. La voz de esta madre resuena en el corazón de Tita, cuando su espíritu indica cómo ayudar a Rosaura en el parto o le dicta la receta prehispánica de codornices con pétalos de rosas. Esta voz, que proviene de las capas más profundas de la psique donde anida la irracionalidad, representa un modo de liberación, la exaltación de la vi$\mathrm{da}^{28}$. Se concreta en el diario-recetario que Tita escribe, donde se funden al mismo tiempo la heredad cultural de la india ${ }^{29}$ (sus recetas y consejos) y la historia personal de Tita. En oposición surgen las numerosas afonías y silenciamientos a los que Mamá Elena ha sometido a Tita y por extensión, el patriarcado al sexo femenino ${ }^{30}$. Porque, en palabras de Luisa Valenzuela:

«(...) la boca sigue siendo el hueco más amenazador del cuerpo femenino: puede eventualmente decir lo que no debe ser dicho, revelar el oscuro deseo, desencadenar las diferencias amenazadoras que subvierten el cómodo esquema del discurso falocéntri$\cos ^{31}$.

A Tita no se le permite cuestionar una orden, replicar o llorar por la muerte de Roberto. Como consecuencia, enmudece y regresa a un estado prelógico inconsciente; Cae a la orden imaginaria, en términos lacanianos. La recuperación de la voz viene de mano de otra madre simbólica, John (figura por demás feminizada) que hace re-nacer a Tita con sus cálidas palabras y con su amor, y del alimento (el caldo de colita de res que Chencha le suministra), materia consustancial a la madre. Esta nueva voz de Tita alcanza diferentes tesituras: voz como grito, aullido, exclamación, premonición o maldición. Como apunta Tina Escaja ${ }^{32}$, la palabra que enuncia Tita tiene un poder demiúrgico y alquímico, pues los
25 En la misma tesitura está el siguiente fragmento de Isabel Allende: «Y entonces, en una oleada de sangre surgió una cabeza cubierta de pelo oscuro (...) Con otro brutal empeño de la madre apareció el resto del cuerpo de mi nieta, un paquete ensangrentado y frágil, el más extraordinario regalo». Isabel Allende, Paula, Barcelona, Círculo de Lectores, 1994, p. 267.

\section{6}

Almudena Grandes, Op.cit., p. 425 .

27

Apud Toril Moi, Teoría feminista, Madrid, Cátedra, 1999, p. 124.

28

Hélène Cixous, Op. cit., p. 56.

29

La adyacencia de Tita al seno de Nacha supone un doble exilio: por un lado del territorio del pa$\mathrm{dre} /$ madre biológicos y por otro, de la cultura de raigambre europea (sus padres son hacendados) a la de origen prehispánico.

\section{0}

El pensamiento homocéntrico ha creado toda una serie de símbolos y mitos que aluden a la mudez como constitucional del sexo femenino o al "robo"prometeico de la palabra: Lilith maldita por pronunciar nombre inefable, por el mismo hecho de nombrar: Procne y Filomela, mujeres sin voz; la Esfinge como monstruo de la palabra desconocida, del enigma.

31

Luisa Valenzuela, «La mala palabra", Revista lberoamericana Pittsburgh, nº 132-133, p. 489.

32

Tina Escaja, Op. cit., p. 577. 
Laura Esquivel, Op. cit., p. 227

34

lbid, p. 62.

35

Lola Beccaría, "Almudena Grandes. El paraíso perdido», El Urogallo. Revista literaria y cultural, Madrid, Ediciones Prensa de la Ciudad, nº97, junio, 1994, p. 59.

36

La importancia de las relaciones femeninas la sostiene Almudena Grandes incluso como programa de vida cuando afirma que consiguió escribir Malena es un nombre de tango al establecer vínculos con otras mujeres más allá de lo circunstancial, en términos de verdadera amistad y entendimiento. Francisco J. Sałué, "Almudena Grandes», El Urogallo. Revista literaria y cultural, Septiembre-Octubre, 1994, n 100-101, p. 25.

37

Efectivamente, "Malena» es el nombre de un tango rioplatense compuesto por Homero Manzi y musicado por Lucio Demare. Inspirado en una mujer de identidad enigmática, este tango simboliza los valores vitales que desbordan el tiempo, los sentimientos, las pasiones, el amor, la propia vida, como Malena.

Como agua para cbocolate y Malena es un nombre de tango: en busca de una genealogía perdida $\overline{\text { PAOLA MADRID MOCTEZUMA }}$ deseos que pronuncia así como las maldiciones que conjura poseen el don maravilloso de cumplirse: la petición ante el muñeco del roscón de reyes de que su madre deje de atormentarla o de que venga Gertrudis se realizan ya que su madre muere y la hija pródiga vuelve a la hacienda; el deseo de que a su hermana se le agusanaran las palabras y pudrieran en el estómago se cumple cuando Rosaura muere de «congestión estomacal aguda»; el exorcismo del fantasma de Mamá Elena surte efecto al gritar Tita que la odia: "Tita pronunció las palabras mágicas para hacer desaparecer al fantasma de Mamá Elena para siempre»33.

El encuentro con el cuerpo de la madre a su vez determina el conocimiento del propio cuerpo y de lo pulsional. Es en la cocina donde la exploración corporal se convierte en apoteosis, baste recordar los momentos en que Tita se disuelve en la comida a través de sus fluidos (sangre untada en pétalos de rosas, lágrimas vertidas sobre un pastel), y penetra en el cuerpo de Pedro cuando éste degusta sus platillos. La aparición de fenómenos específicamente femeninos como la menstruación, el parto o la lactancia y las relaciones sexuales forman parte del proceso de autoconocimiento que se gesta en Tita, hiperbolizado en un orgasmo cósmico final que la transporta al edén perdido. No sólo Nacha y Tita conforman esta saga femenina puesto que en la novela aparecen más mujeres movidas por pasiones comunes, como el conocimiento, el erotismo y la libertad; se trata de Gertrudis, Luz del Amanecer y Esperanza. La primera de ellas, Gertrudis, es hija bastarda y de sangre mestiza. Canaliza toda su energía libidinal al través del erotismo, y es quien ejerce con mayor explicitud su actitud subversiva. Prostituta, soldade$\mathrm{ra}$, generala, entronca con una rama femenina que históricamente existió en el México de comienzos del siglo XX. Se trata de mujeres aguerridas que lucharon por la causa revolucionaria al lado de sus compañeros. La famosa Adelita, Valentina, «La Cucaracha» o María Arias Bernal, «María Pistolas» son los nombres más populares de este tipo de soldadera, a caballo entre el mito y la historia. La función de Gertrudis en la novela es la de hacer de mediadora de los amores entre Tita y Pedro:

«Parecía que habían descubierto un código nuevo de comunicación en el que Tita era la emisora, Pedro el receptor y Gertrudis la afortunada en quien se sintetizaba esta singular relación sexual, a través de la comida»34

Gertrudis además, revela a Pedro el supuesto embarazo de Tita, persuade a ésta sobre métodos anticonceptivos y es en su cama donde los amantes consuman su amor. Por su parte, Luz del Amanecer, al igual que Nacha, es una Madre primigenia en la que convive la síntesis de lo mágico y ancestral. Pero el eslabón de esta cadena que más similitudes guarda con Tita es Esperanza (nombre de alto contenido simbólico); en ella culmina el programa de liberación femenina que comienza con su tía Tita; no es casualidad que una serie de coincidencias las unan (mismos gustos culinarios, partos prematuros, llanto en el interior del vientre materno clamando por salir) y de este modo, la genealogía se cierra como empieza, con la salvedad de que esta mujer lleva las riendas de su propia vida.

En el caso de la novela de Almudena Grandes la desesperada búsqueda de las raíces simbólicas responde al deseo de Malena de justificar su naturaleza supuestamente corrompida. Se trata de una obra que "nos muestra en fin el dilema trágico del no saber de qué lado del bien o el mal está uno, del desarraigo existencial dentro de la propia estirpe, y del camino heroico, épico en grado sumo, para encontrarse de nuevo en un ámbito de libertad ganado a base de dejarse la piel y el alma, pagando el precio de la soledad o la marginación» ${ }^{35}$. Ese ámbito de libertad será conquistado en la medida en que la protagonista viaje a través del espejo y se encuentre con otras, como ella, que le devuelvan el reflejo adecuado ${ }^{36}$.

Magdalenas penitentes, Magdas pecadoras, Malenas que cantan tangos, que los inspiran $^{37}$, todas portadoras del estigma que las hace inconfundibles: la posesión de una fuerza vital arrolladora. Magda y Malena, la misma imagen reflejada en un espejo, hechas de la misma carne voluptuosa e idéntica sangre espesa y maldita. Su relación especular incardina toda la novela. Desde su comienzo se nos dice:

«(...) todos parecían calcular que yo sería el único ser de este mundo capaz de llorar la desaparición de Magda, como si las dos perteneciésemos a una especie aparte. Rehuí la mirada de mi madre. Yo la ama- 
ba (...) pero su hermana me reflejaba como en un espejo, y los espejos rotos solamente traen desgracias $»^{38}$

Magda será la madre simbólica de Malena ${ }^{39}$ (aunque desde la lejanía), que le ayuda a aceptar sus propias tendencias vitales como fuente de placer, conocimiento y vida. Para ello comienza por convencerla de que la negación de su cuerpo (Malena quiere ser un chico) y de su identidad natural (mediante «el Juego») no son soluciones que la ayuden a reencontrarse consigo misma. Cuerpo como "destino turbio», como "campo de batalla» o como «moco seco», "cuerpo prestado, ajeno, cautivo» son frases que se se repiten a lo largo de la novela. Pero será un cuerpo de caderas rotundas, «pezones de color violeta» $\mathrm{y}$ «labios de india» el que permita a Malena adentrarse en su sexualidad múltiple y difusa, lo que Luce Irigaray denomina jouissance, caracterizada por una epifanía sensorial diversificada y heterogénea:

«Fernando enmudecía mientras me desnudaba con dedos torpes (...) y yo me dejaba despojar hasta el último de mis velos transparentes y callaba con él, hasta que su dedo índice empapado en el espeso jarabe marrón que nuestro calor y nuestro sudor habían hecho brotar en la blanda superficie de las hojas prensadas, empezaba a pasear sobre mi piel (...) Yo a veces me atrevía a escribir mi nombre sobre su pecho y luego lo borraba con la lengua, y hallaba un placer inexplicable en el acérrimo amargor de aquella sustancia donde se confundían el sabor de Fernando y el sabor del tabaco» ${ }^{10}$.

Gracias a Magda, la reconciliación de Malena con su cuerpo es absoluta: su temor a envejecer se disipa cuando contempla a su tía, con el cuerpo desnudo y derrumbado, surcado por arrugas pero en enigmática armonía con el universo.

La voz de Malena como conquista plena de la libertad está impulsada también por Magda. Gracias al diario que le regala, Malena inicia una paulatina recuperación de su palabra. Esta introducción a la escritura permitirá a Malena empezar a adueñarse de su vida y a quererse tal y como es:

«Querido diario, me llamo Magdalena, pero todos me llaman Malena, que es un nombre de tango. Hace casi un año que tengo la regla, así que me parece difícil que la Virgen quiera convertirme en un chico, y creo más bien que voy a ser un desastre de mujer, igual que Magda ${ }^{4}{ }^{41}$

Pero del mismo modo que le ocurre a Tita, esta voz será acallada por el patriarcado, representado por Reina. Ésta le roba el diario, lo tacha, lo corrige, se lo apropia en un deseo irrefrenable de adueñarse de la identidad de su hermana. La pérdida del diario representa para Malena la mudez simbólica. Será tras su recuperación cuando Malena reencuentre su cuerpo, el recuerdo de su amor, el tono justo de su voz y será sólo entonces cuando ésta conjure una maldición hacia Reina y toda su genealogía:

"-Maldita seas, Reina (...), y malditas sean tus hijas, y las hijas de tus hijas, y que por vuestras venas corra siempre un líquido perfecto, transparente, claro y limpio como el agua, y que jamás, en toda vuestra vi$\mathrm{da}$, ninguna de vosotras llegue a saber nunca lo que significa tener una sola gota de sangre podrida ${ }^{42}$.

\section{La deuda está saldada.}

Hemos asistido al proceso de reconstrucción del sujeto femenino en dos novelas contemporáneas de habla hispana; el trazado de un entramado simbólico o la reinterpretación de hechos como la maternidad, la relación de la mujer con su propio cuerpo y la rehabilitación de su voz nos permiten afirmar que $\mathrm{Ma}$ ría Magdalena González de Alcántara y Josefa de la Garza se han logrado desasir del lastre paterno para pasar simplemente como Malena o Tita al árbol genealógico de nuestra memoria.

\section{BIBLIOGRAFIA}

BECCARÍA, Lola C., «Almudena Grandes. El Paraíso perdido", El Urogallo. Revista literaria y cultural, Madrid, Ediciones prensa de la Ciudad, nº 97, junio, 1994.

CIPLIJAUSKAITÉ, Biruté, La novela femenina contemporánea (1970-1985). Hacia una tipologia de la narración en primera persona, Barcelona, Anthropos, 1988.

CIXOUS, Hélène, La risa de la medusa, Barcelona, Anthropos, 1995.

CRÓQUER PEDRÓN, Eleonora, El gesto de Antígona o la escritura como responsa-
38

Almudena Grandes, Op. cit., p. 31.

39

Este tipo de maternidad simbólica Almudena Grandes la explorará también en el relato "La buena hija» incluido en Modelos de mujer (Almudena Grandes, Modelos de mujer, Barcelona, Círculo de Lectores, 1996, pp. 215-274).

40

Ibid, pp. 208-209.

41

Ibid, p. 91

42

Ibid, p. 541

Como agua para chocolate y Malena es un nombre de tango: en busca de una genealogía perdida PAOLA MADRID MOCTEZUMA 
bilidad (Clarice Lispector, Diamela Eltity Carmen Boullosa), Santiago, Cuarto Propio, 2000.

CHIRIVELLA, Carmen, "Almudena Grandes. Malena es un nombre de tango", Diablotexto, Revista de Critica literaria, Valencia, Universidad de Valencia, $\mathrm{n}^{\circ}$ 2, 1995.

ESCAJA, Tina, «Reinscribiendo a Penélope: mujer e identidad mexicana en Como agua para chocolate", Revista Iberoamericana, Pittsburgh, vol. LXVI, $\mathrm{n}^{\circ}$ 192, Julio-septiembre, 2000.

ESQUIVEL, Laura, (1989), Como agua para chocolate, Barcelona, Mondadori, 2000.

ETCHEGOYEN, Regina, «Como agua para chocolate: experiencia culinaria y autorrealización femenina», Cuadernos hispanoamericanos, Madrid, Enero, $\mathrm{n}^{\circ}$ 547, 1991.

GLANTZ, Margo, "Las hijas de la Malinche», Karl KHOUT (ed.), Literatura mexicana boy, Madrid, Iberoamericana, 1995.

GONZÁLEZ STEPHAN, Beatriz, «'Para comerte mejor': cultura calibanesca y formas literarias alternativas», Casa de las Américas, 185, 1991.

GRANDES, Almudena, (1994), Malena es un nombre de tango, Barcelona, Tusquets Editores, 1999.

- (1996), Modelos de mujer, Barcelona, Círculo de lectores, 1996.

IRIGARAY, Luce, El cuerpo a cuerpo con la madre. El otro género de la naturaleza. Otro modo de sentir, Barcelona, Labal, 1995.

- "Cuando nuestros labios se hablan», Ese sexo que no es uno, Madrid, Saltés, 1982.

- «Ese sexo que no es uno», Ese sexo que no es uno, Madrid, Saltés, 1982.

LÓPEZ GONZÁLEZ, Aralia, «Ética y estética del fuego», Aralia LÓPEZ GONZÁLEZ (ed.), Sin imágenes falsas, sin falsos espejos. Narradoras mexicanas del siglo XX, México, El Colegio de México, 1995.
- «Nuevas formas de ser mujer en la narrativa contemporánea de escritoras mexicanas", Casa de las Américas, La Habana, 183, 1991.

MOI, Toril, Teoría literaria feminista, Madrid, Cátedra, 1999.

NICHOLS, Geraldine C., Des/cifrar la diferencia, Narrativa femenina de la España contemporánea, Madrid, Siglo Veintiuno, 1992.

- Escribir, espacio propio: Laforet, Matute, Moix, Tusquets, Riera y Roig por sí mismas, Minneapolis, Institute for the Study of Ideologies and Literature, 1989.

PEÑARANDA, Rosario, «Narradoras latinoamericanas de los ochenta en la «salsa» de la escritura», Sonia MATTALÍA y Milagros ALEZA (eds.), Mujeres: escrituras y lenguajes, Valencia, Universidad de Valencia, 1995.

REISZ, Susana, «Hipótesis sobre el tema «Escritura femenina e hispanidad», Tropelias. Revista de teoría de la literatura y literatura comparada, $\mathrm{n}^{\circ} 1$, Zaragoza, Universidad de Zaragoza, 1990.

RICH, Adrienne, Nacemos de mujer. La maternidad como experiencia e institución, Madrid, Cátedra, 1996.

RODRÍGUEZ MAGDA, Rosa María, «La genealogía como proyecto transmoderno», $\mathrm{M}^{\mathrm{a}}$ Carmen África VIDAL CLARAMONTE y Teresa GÓMEZ REUS (eds.), Abanicos excéntricos. Ensayos sobre la mujer en la cultura posmoderna, Alicante, Universidad de Alicante, 1995.

ROSAS ROBLES, Alejandro, «Historia: las mujeres», en www.letraslibres.com

SATUÉ, Francisco J., «Almudena Grandes», El Urogallo. Revista literaria y cultural, Madrid, Ediciones Prensa de la Ciudad, Septiembre-Octubre, nº 100-101, 1994.

VALENZUELA, Luisa, «La mala palabra», Revista Iberoamericana, Pittsburgh, $\mathrm{n}^{\circ} 132-133$. 